\title{
An Economic Study of Onion Group Production and Exporting in Egypt
}

Ali, E. H. A.

Agricultural Economics Research Institute

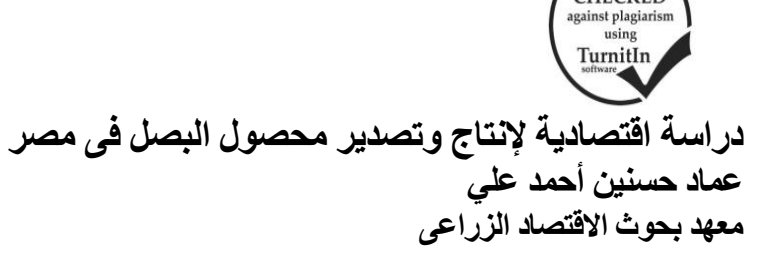

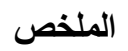

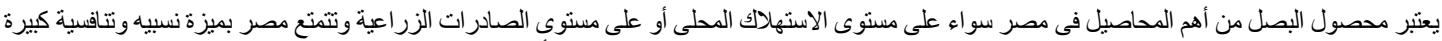

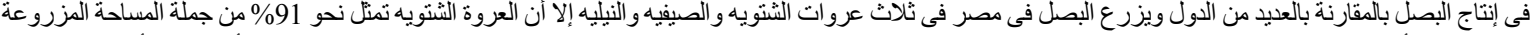

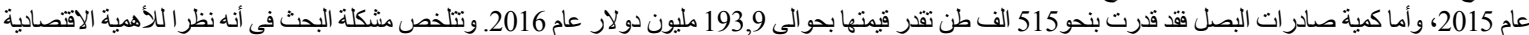

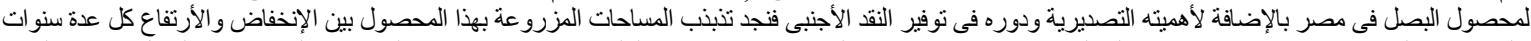

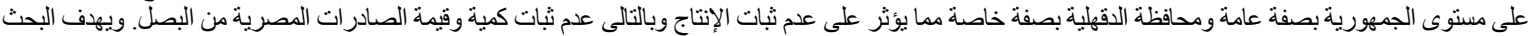

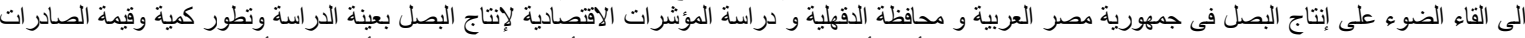

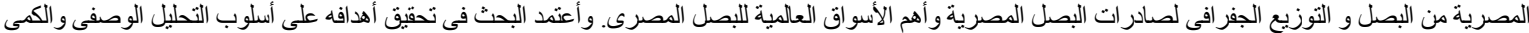

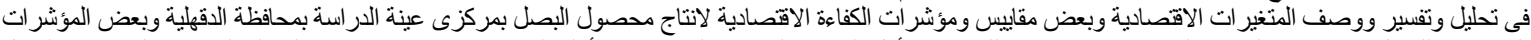

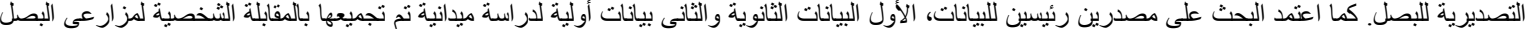

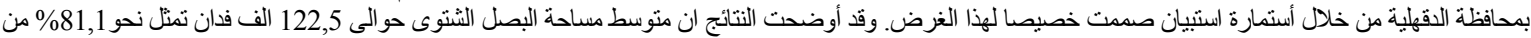

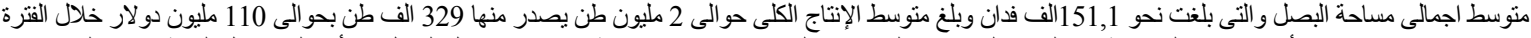

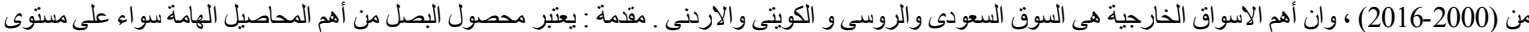

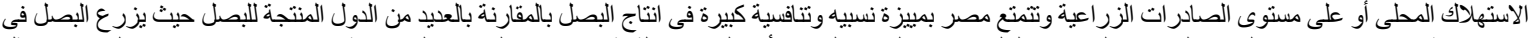

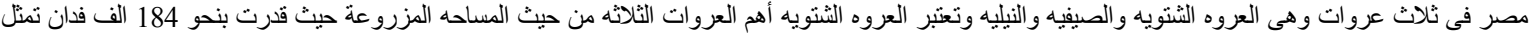

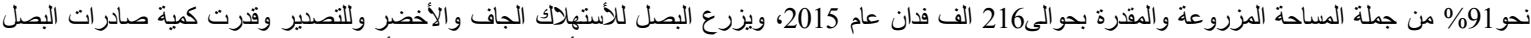

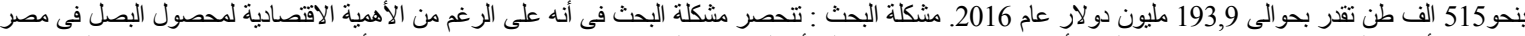

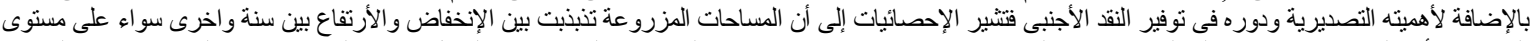

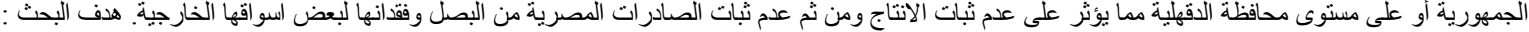

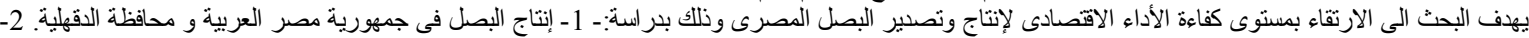

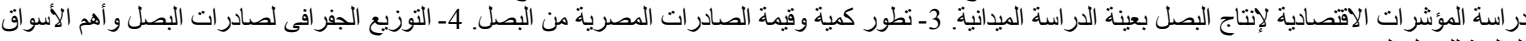
العالمبة للبصل المصرى.

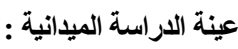

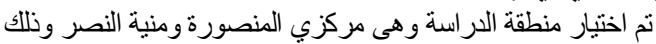

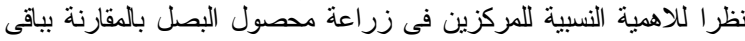

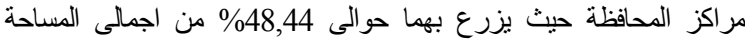

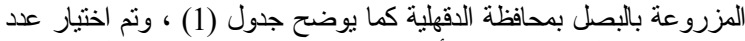

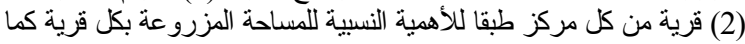

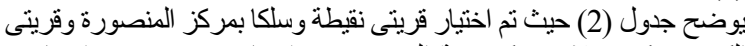

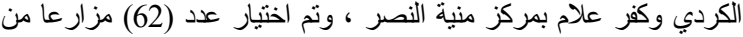

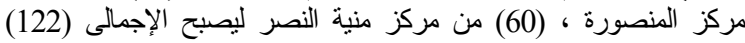

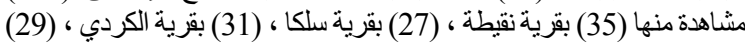

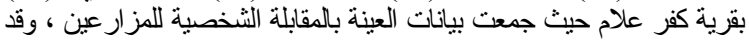

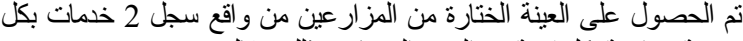

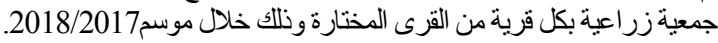
جدول 2. توزيع حجم العينة لمحصول البصل على المرئل المراكز والقرى المختارة

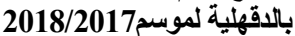

\begin{tabular}{|c|c|c|c|c|c|c|c|}
\hline للجرية العينة & للقريتين & المساحة) & القرية & للمجر العينة & للمركزين & (ألمانحة) & ركز \\
\hline 35 & 56,25 & 540 & نقيطة & & & & \\
\hline 27 & 43,75 & 420 & سلكا & 62 & 50,97 & 4678 & المنصورة \\
\hline 62 & 100 & 960 & الجملة & & & & \\
\hline 31 & 52,27 & 460 & الكردي & & & & \\
\hline 29 & 47,73 & 420 & كفر علام & 60 & 49,03 & 4500 & 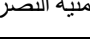 \\
\hline 60 & 100 & 880 & الجملة & 122 & 100 & 9178 & ملة \\
\hline
\end{tabular}

اولا : الوضع الاتتاجى الراهن للبصل فى جمهورية مصر العربية ومحافظة

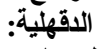

1- تطور المساحة المزروعة والانتاجية القدانية والانتاج الكلى للبصل على مستوى الجمهورية:

يشير جدول(3) الى تطور المساحة المزروعة بمحصول البصل

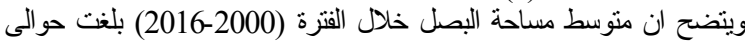

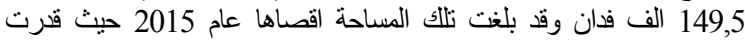
بحو الى216 الف فدان بزيادة نقار بنحو 66,5 الف فدان عن المتوسط العام خلال

\section{الطريقة البحثية}

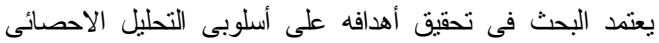

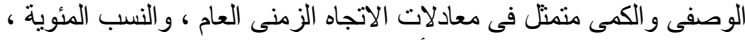

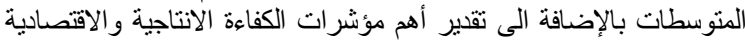

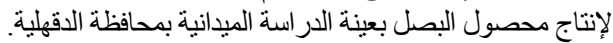

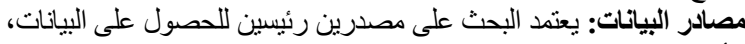

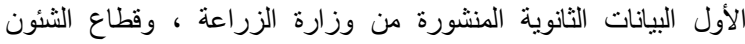

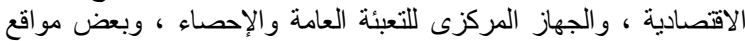

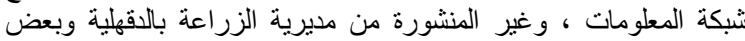

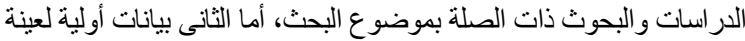

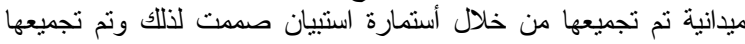

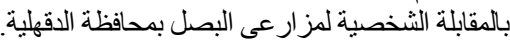

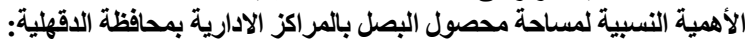

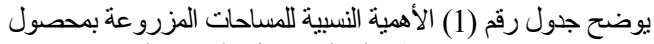

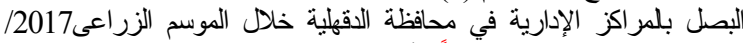

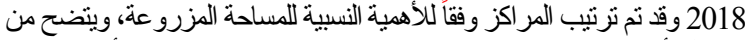

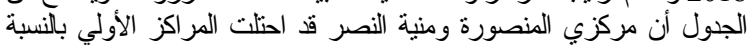

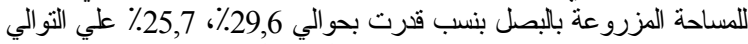

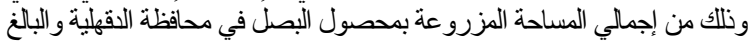

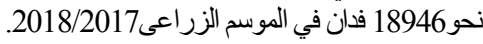

جلول 1. الأهمية النسبية لمساحة محصول البصل بالمباكراكز الادارية

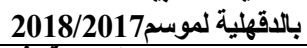

\begin{tabular}{|c|c|c|}
\hline$\%$ & المساحة (فدان) & المركز \\
\hline 24,69 & 4678 & المنصورة \\
\hline 23,75 & 4500 & ية النصر \\
\hline 18,47 & 3500 & $i$ \\
\hline 14,78 & 2800 & سنبلاوين \\
\hline 9,24 & 1750 & ينزلة \\
\hline 4,10 & 776 & ت سويد \\
\hline 1,27 & 240 & ربين \\
\hline 1,05 & 200 & ت غمر \\
\hline 2,65 & 502 & يرى \\
\hline 100 & 18946 & لـة المحافظة \\
\hline
\end{tabular}




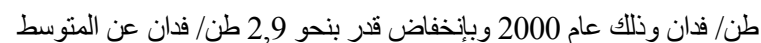

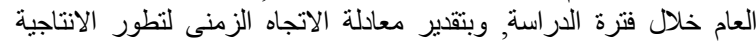

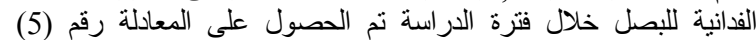

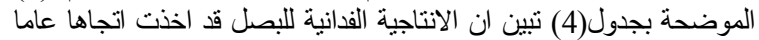

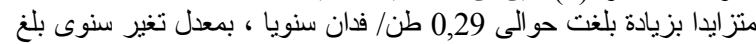

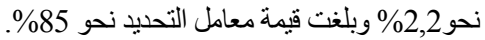

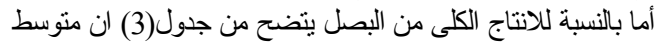

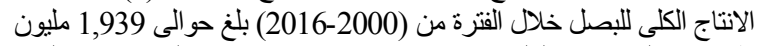

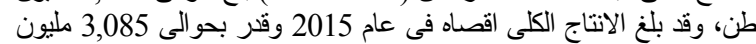

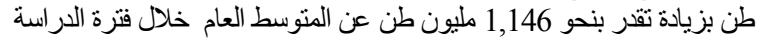

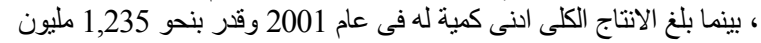

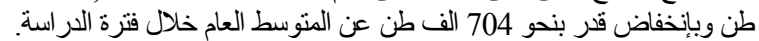

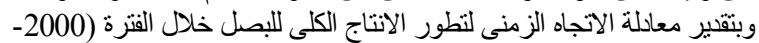

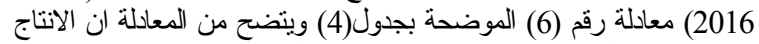

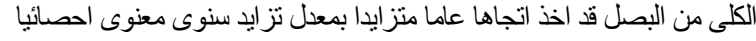

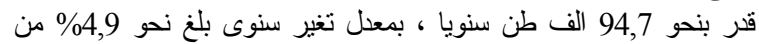

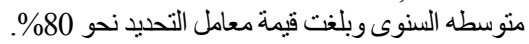
جدول 3 ـتطور المساحة بالالف فان وان والانتاجية بالطن والانتاج بالالف طن لمحصول البصل خلال الفترة (2000-2016)

\begin{tabular}{|c|c|c|c|c|c|c|c|c|c|}
\hline نتاج & & المساحلة & $\%$ & مسناحة & $\%$ & الصسيفي & $\%$ & الثتناحي & $ت$ \\
\hline 1270 & 10 & 127 & 4,7 & 6 & 19,7 & 25 & 75,6 & 96 & 2000 \\
\hline 1235 & 10,2 & 121 & 8,3 & 10 & 24,8 & 30 & 66,9 & 81 & 2001 \\
\hline 1488 & 10,6 & 140 & 7,2 & 10 & 19,3 & 27 & 73,5 & 103 & 2002 \\
\hline 1242 & 11,2 & 110 & 8,2 & 9 & 21,8 & 24 & 70 & 77 & 2003 \\
\hline 1612 & 11,9 & 135 & 8,2 & 11 & 20,7 & 28 & 71,1 & 96 & 2004 \\
\hline 1925 & 12,3 & 156 & 3,8 & 6 & 12,8 & 20 & 83,4 & 130 & 2005 \\
\hline 1346 & 12,3 & 109 & 8,3 & 9 & 20,2 & 22 & 71,5 & 78 & 2006 \\
\hline 1756 & 12,6 & 139 & 10,8 & 15 & 12,9 & 18 & 76,3 & 106 & 2007 \\
\hline 1949 & 13,1 & 148 & 7,4 & 11 & 10,2 & 15 & 82,4 & 122 & 2008 \\
\hline 2129 & 13,5 & 157 & 8,3 & 13 & 9,5 & 15 & 82,2 & 129 & 2009 \\
\hline 2304 & 13,9 & 165 & 7,9 & 13 & 10,3 & 17 & 81,8 & 135 & 2010 \\
\hline 2305 & 13,8 & 166 & 10,3 & 17 & 7,8 & 13 & 81,9 & 136 & 2011 \\
\hline 2199 & 13,7 & 160 & 6,3 & 10 & 5,6 & 9 & 88,1 & 141 & 2012 \\
\hline 2115 & 14,4 & 146 & 8,2 & 12 & 5,5 & 8 & 86,3 & 126 & 2013 \\
\hline 2680 & 14,5 & 184 & 5,4 & 10 & 3,8 & 7 & 90,8 & 167 & 2014 \\
\hline 3085 & 14,2 & 216 & 5,1 & 11 & 3,7 & 8 & 91,2 & 197 & 2015 \\
\hline 2318 & 14,2 & 163 & - & $*_{-}$ & - & $*_{-}$ & 100 & 163 & 2016 \\
\hline 1939 & 12,9 & 151,1 & 7,1 & 10,8 & 11,8 & 17,8 & 81,1 & 122,5 & المتوسط \\
\hline
\end{tabular}

\begin{tabular}{|c|c|c|c|c|c|c|c|c|c|}
\hline قيمة F للمعادلة المحسوية & Tقالمحسوية & $\begin{array}{c}\text { معامليد } \\
\text { R التحليد }\end{array}$ & السنوى \% \% التيل) & متوسط الفترة & معامل الآحدار & الثَابت & الوحدة & المتفير & م \\
\hline 41,9 & 6,47 & 0,74 & 4,6 & 122,5 & 5,67 & 71,5 & الف فدان & مساحة الثتوى & $\overline{1}$ \\
\hline 144,4 & ${ }^{* *} 12,01-$ & 0,91 & $3,3-$ & 17,8 & $0,59-$ & 9,1 & الف فدان & مساحة الصبفى & 2 \\
\hline${ }^{* *} 3,92$ & ${ }^{*} 1,98$ & 0,22 & 0,6 & 10,8 & 0,28 & 8,43 & الف فدان & & 3 \\
\hline${ }^{* *} 21,34$ & 4,62 & 0,59 & 2,7 & 149,5 & 4,06 & 112,9 & الف فدان & اجمالى المساحة & 4 \\
\hline${ }^{* *} 171,61$ & ${ }^{* *} 13,1$ & 0,92 & 2,2 & 12,9 & 0,29 & 10,18 & طن/فدان & الإنتاجية & 5 \\
\hline${ }^{* *} 62,56$ & ${ }^{* *} 7,91$ & 0,80 & 4,9 & 1939 & 94,7 & 1086,6 & الف طن & الإنتاج & 6 \\
\hline
\end{tabular}

بلغ حوالى 12,82 طن/ فدان وقد تراوحت تللك الانتاجية بين حد النى بلغ فئغ

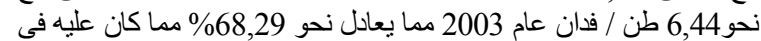

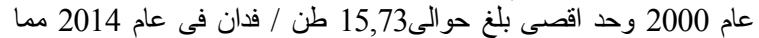
يعادل نحو 166,81\% مما كان عليه في عام الإنير 2000.

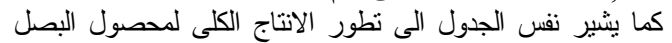

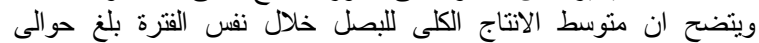

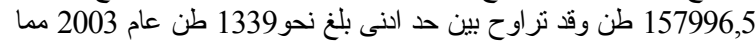

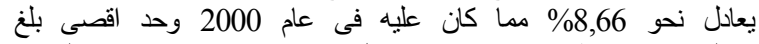

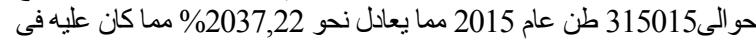
عام 2000.

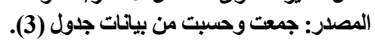

فترة الدراسة ، بينما بلغت ادناها بنحو 109 الف فدان وذلك الك عام 2006

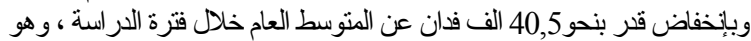

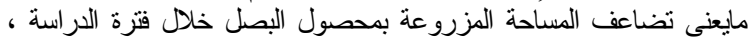

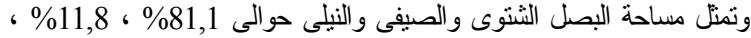

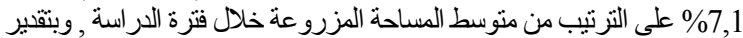

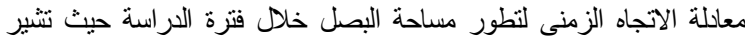

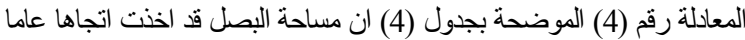

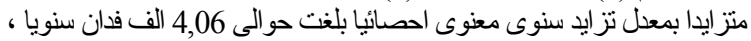

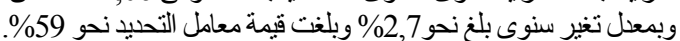
* ويثير جدول(3) الى أن متوسط مساحة البصل الثنتوى خلال الفترة (2000-

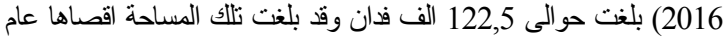
2015 حيث قدرت بحو الى197 الف فدان بزيادة تقدر بنحو 74,5 الف فدان

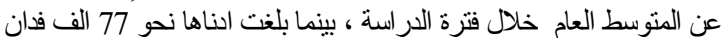

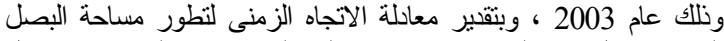

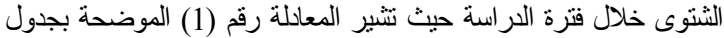

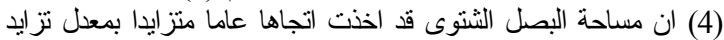

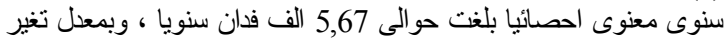

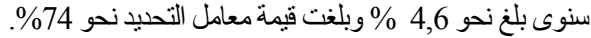

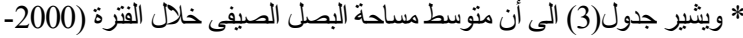
2015) بلغت حوالى 17,8 الف فدان وقد بلغت تلألك المساحة اقصاها عام

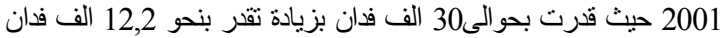

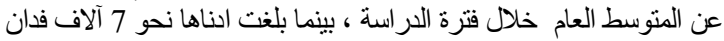

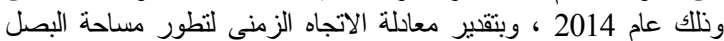

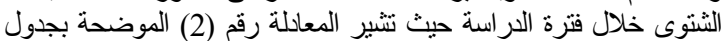

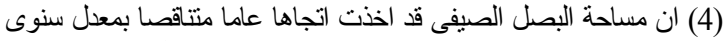

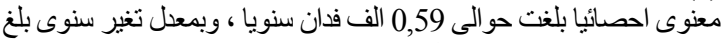

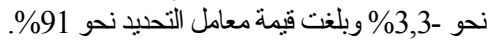
* ويثير جدول(3) الى أن متوسط مساحة البصل النيلى خلال الفترة الفرة (2000-

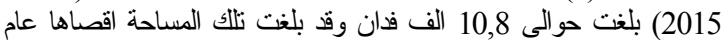

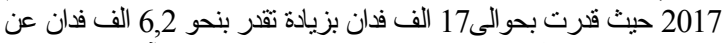

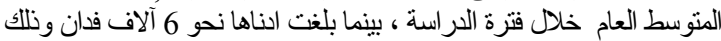
عام 2000 ، وبتقلير معادلة الاتجاه الزمنى لتطور مساحة البصل النيلى النيلى خلال

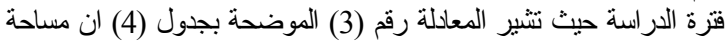

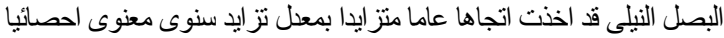

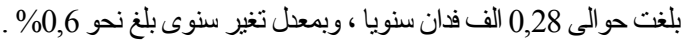

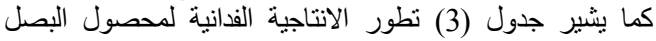

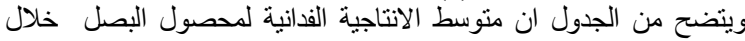

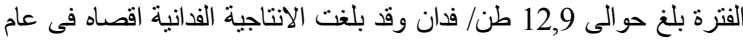

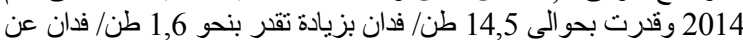

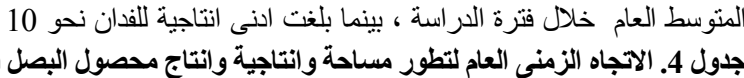

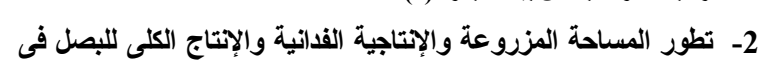
محافظة الاقهلية:

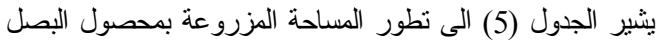

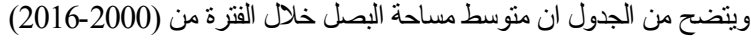

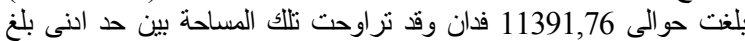

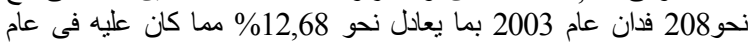

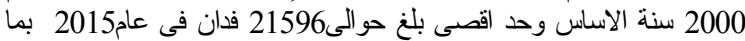

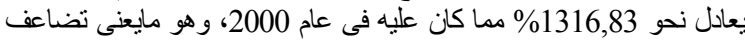

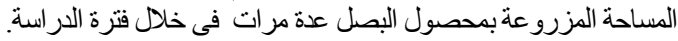

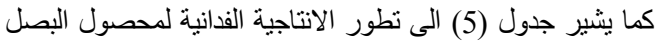

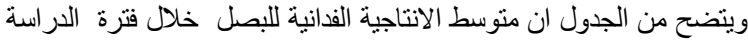




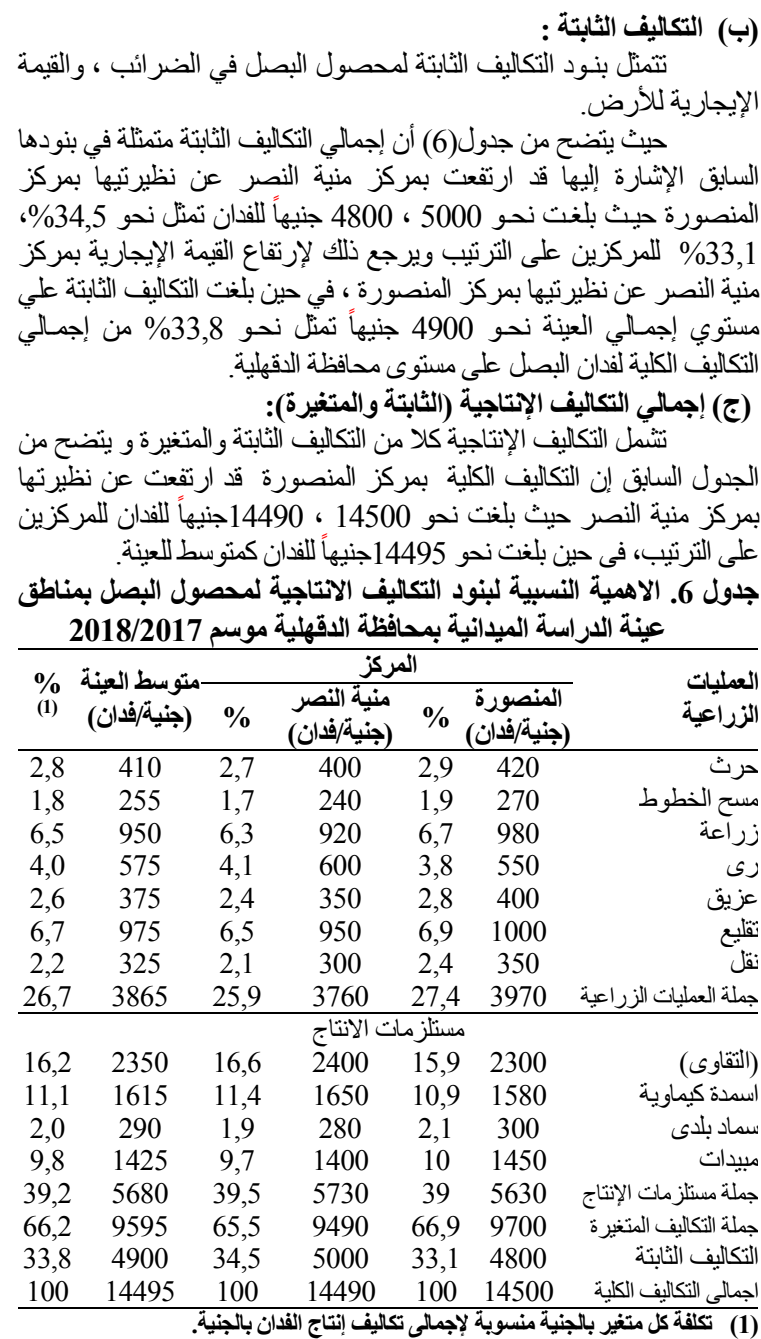

المصدر : جمعت وحسبت من عينة الدراسة الميدانية.

ثالثا:مؤشرات الكفاعة الاقتصادية لمزارعي محصول البنة البصل فيدة في محافظة الاقهلية:

تعتبر مقاييس الكفاءة الإنتاجية والاقتصادية من أدوات التحليل

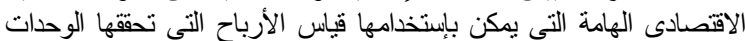

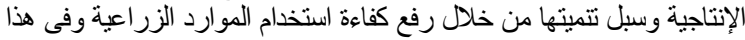

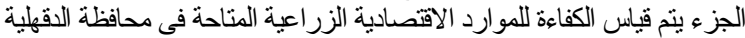

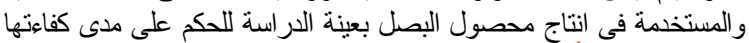
ويمكن قياسها وفقاً لعدة مقاييس وفيما يلي أهم تللك المقاييس و أهمية استخدام كل

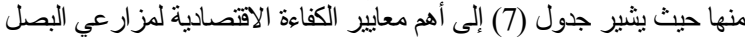

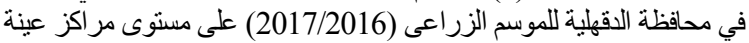

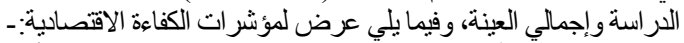

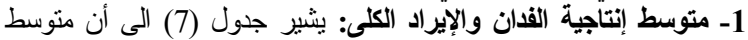

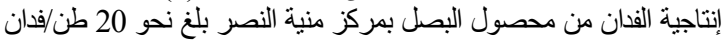

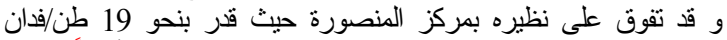

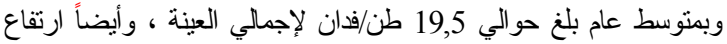
الإيراد الكلى لفدان البصل بمركز منية النصر حيث لإحلغ بلغ نحو 30360

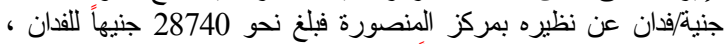

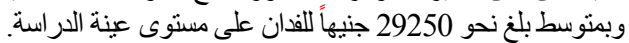

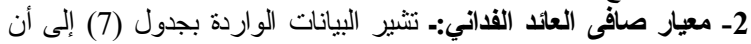

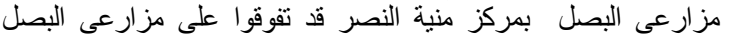

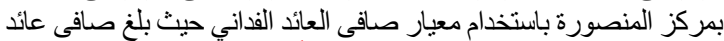

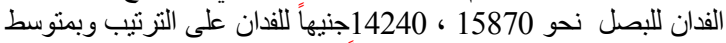
لإجمالي العينة بلغ حو الى لـ 15052جنيهاً للفدان.
جدول 5. الارقام القياسية لمساحة وانتاجية وانتاج البصل بمحافظة الدقهية (2016-2000) للفترة

\begin{tabular}{|c|c|c|c|c|c|c|}
\hline القياسى & $\begin{array}{l}\text { الإنتاج) } \\
\text { (طن) }\end{array}$ & القياسى & الإنتاجية & القياسىى (1) & (فلدسانة) & 19 \\
\hline 100 & 15463 & 100 & 9,43 & 100 & 1640 & 2000 \\
\hline 20,16 & 3117 & 107,95 & 10,18 & 18,66 & 306 & 2001 \\
\hline 19,21 & 2970 & 26,94 & 11,97 & 15,12 & 248 & 2002 \\
\hline 8,66 & 1339 & 3,29 & 6,44 & 12,68 & 208 & 2003 \\
\hline 654,61 & 101222 & 127,89 & 12,06 & 511,59 & 8390 & 2004 \\
\hline 1424,24 & 220230 & 122,27 & 11,53 & 1164,27 & 19094 & 2005 \\
\hline 729,28 & 11 & 120,68 & 11 & 60 & 9907 & 2006 \\
\hline 1,86 & & 1. & 12 & 860 & 4113 & 2007 \\
\hline, 73 & 1 & 13 & 13 & 73 & 65 & 20 \\
\hline 3,01 & 90 & 98 & 36 & 78 & 367 & 2009 \\
\hline, 13 & 271086 & 154,93 & 14,61 & 113 & 18555 & 2010 \\
\hline 1760,51 & 272228 & 160,45 & 15,13 & 1097,38 & 17997 & 2011 \\
\hline ,21 & 150178 & 22 & 15,58 & 587,56 & 9636 & 2012 \\
\hline 1030,89 & 159407 & 164,16 & 15,48 & 628,05 & 10300 & 2013 \\
\hline 1874,08 & 289789 & 166,81 & 15,73 & 1123,05 & 18418 & 2014 \\
\hline 2037,22 & 315015 & 154,72 & 14,59 & 1316,83 & 21596 & 2015 \\
\hline 1570,33 & 242820 & 142,84 & 13,47 & 1098,78 & 18020 & 2016 \\
\hline- & 157996,5 & - & 12,82 & - & 1391,76 & المتوسط \\
\hline
\end{tabular}

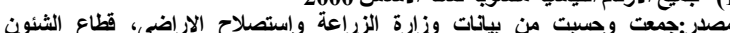

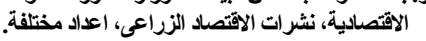

ثانيا: هيكل تكاليف إنتاج محصول البصل بمحافظة الدقاقلية:

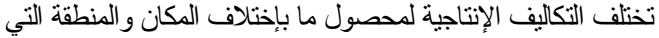

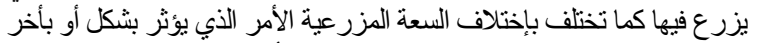

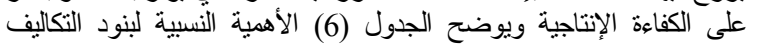

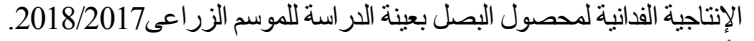
(أ): الأتكاليف المتغيرة : (1)

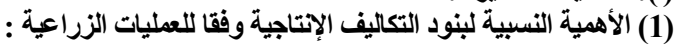

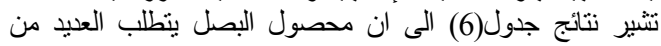

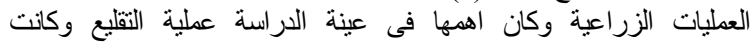

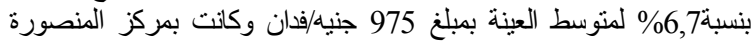

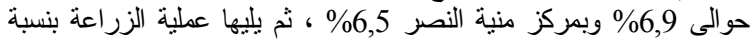

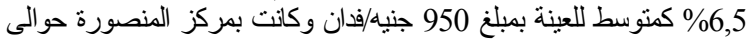

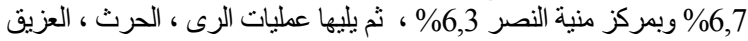

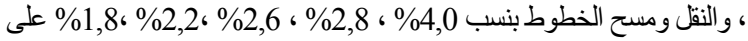
الترتيب من اجمالى التكاليف الكلية لمتوسط العينة ، ويتبن ان المالى العمليات

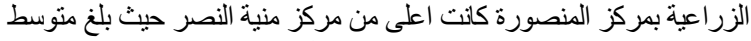

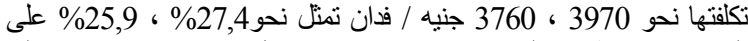

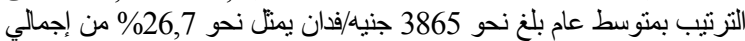

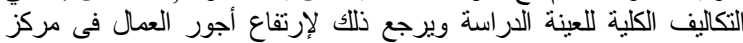
المنصورة عن مركز منية النصر.

(2) الأهمية النسبية لبنود التكاليف الإنتاجية وفقا لمستلزمات الانتاج:

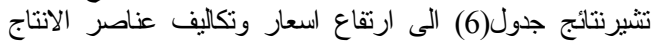

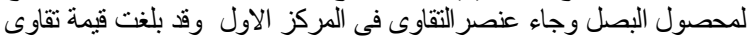

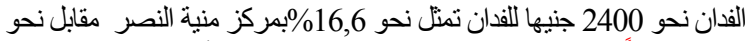

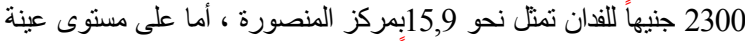

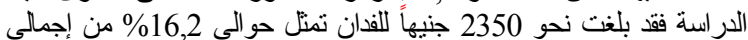
التكاليف الكلية ، ثم عنصر الاسمدة الكيماوية فى المركز الثنانى وقد بلغت تكاليفه

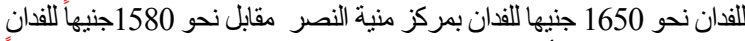

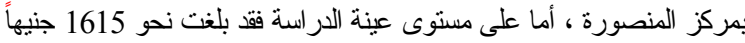

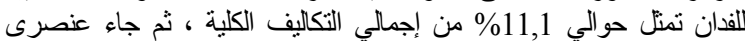

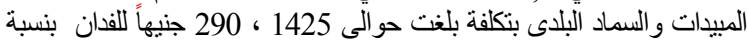

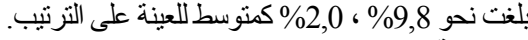
(3) جملة التكاليف المتغيرة:

تشير نتائج جدول (6) إلى أن جملة التكاليف المتغيرة قد ارتفعت

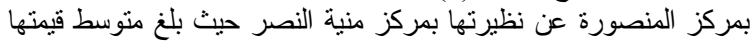

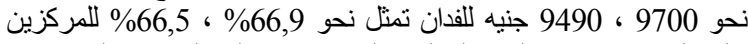

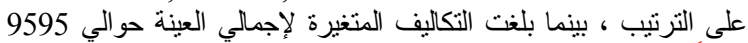
جنيهاً للفدان بنسبة 66,2\% من إجمالي التكاليف الكلية. 
رابعا:الوضع التصديرى الراهن للبصل:

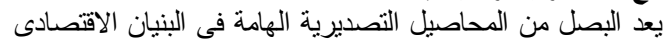

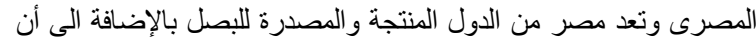

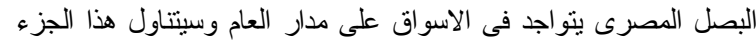

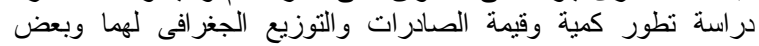

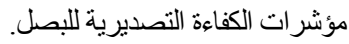

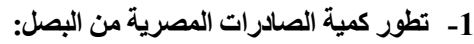

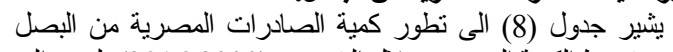

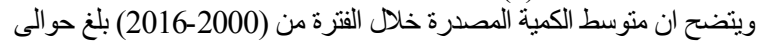
329,2 الف طن وقد بلغت تلك الكمية اقصاها عام 2015 حيث قدرت

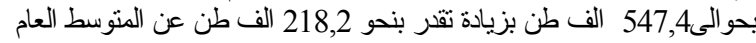

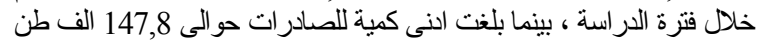

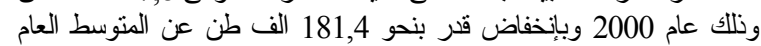

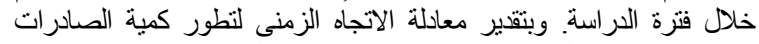

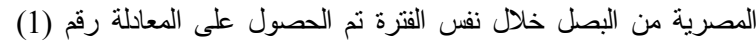

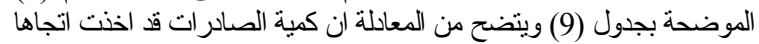

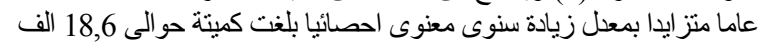

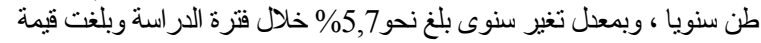

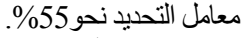

2- تطور قيمة الصادرات المصرية من البصل(بالمليون دولار):

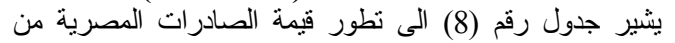

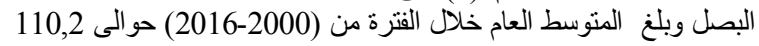

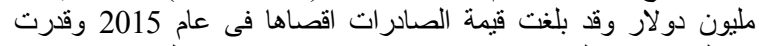

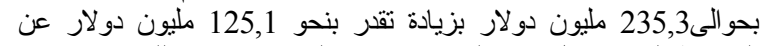

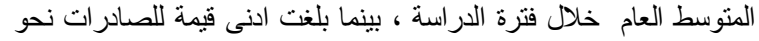

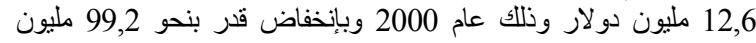

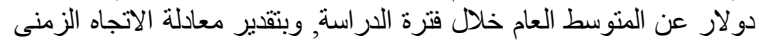

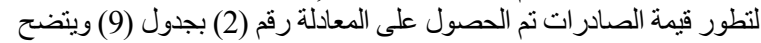

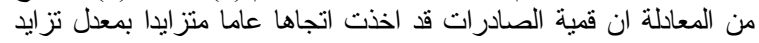

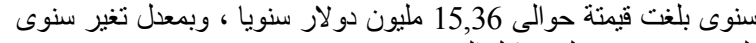

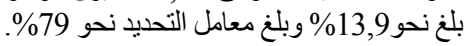

جدول 8. تطور كمية وقيمة الصادرات المصرية من البصل وسلور وسعرالطن

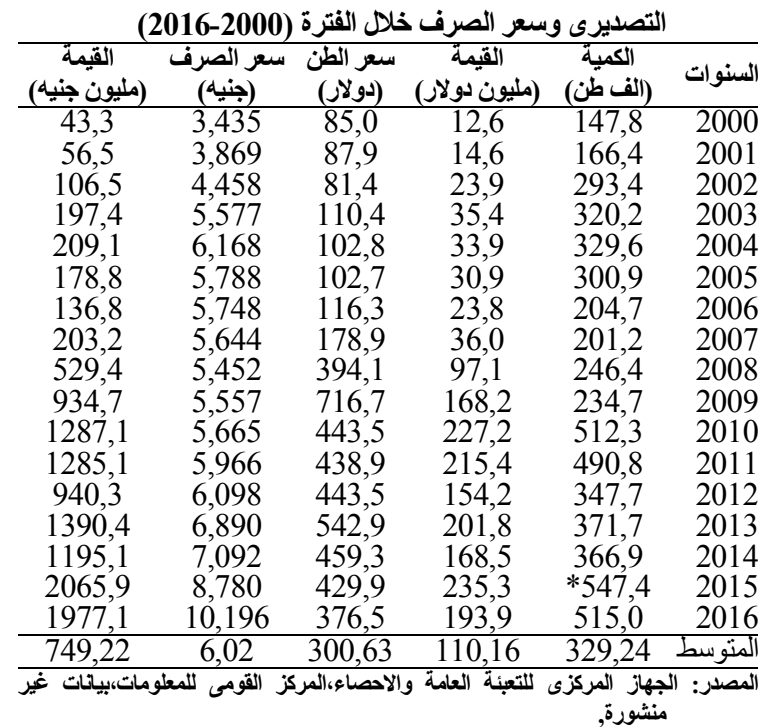

*الاتحاد العام لمنتجى' ومصدرى الحاصلات البستاتية ، بياتات غير منشورة,

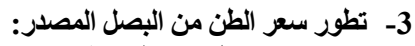

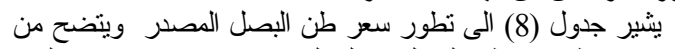

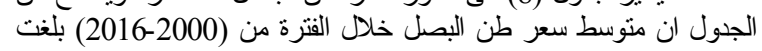

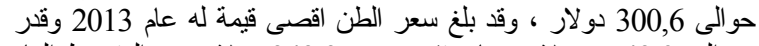

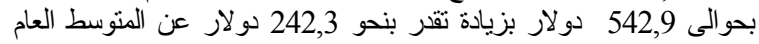

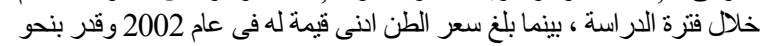

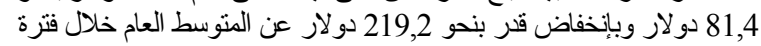

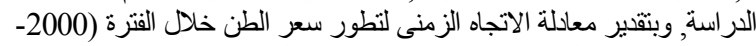
2016) تم الحصول على المعادلة رقم (3) بجدول(9) ويتضح النّر ان سعر الطن

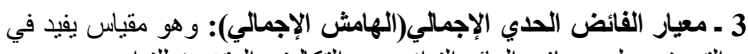

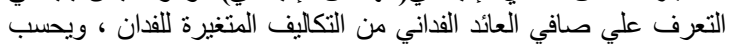
بطرح التكاليف المتغيرة من الإير أد الكلي.

كما اتخذ معيار الفائض الحدي الإيرالئي الإجمالي للفدان نفس مسار المعيار

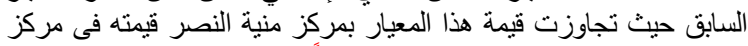

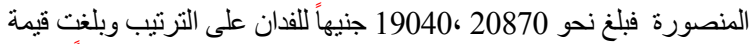

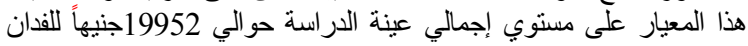

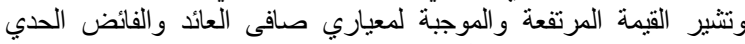

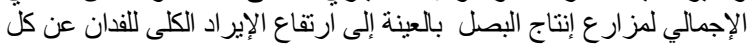

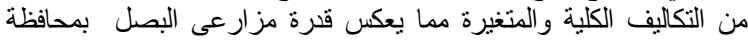

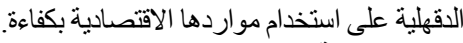

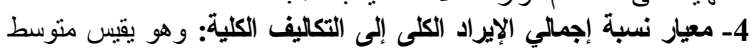

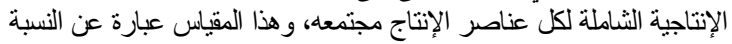

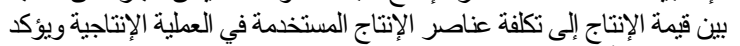

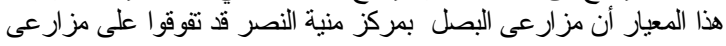

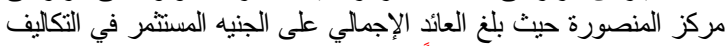

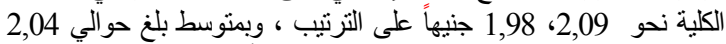

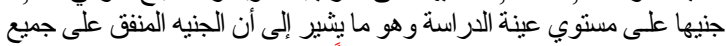

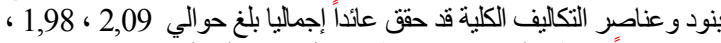

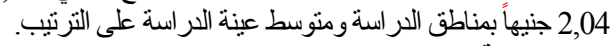

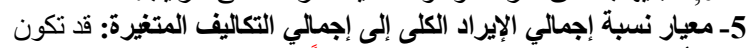

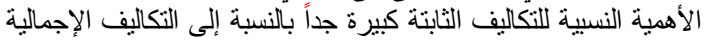

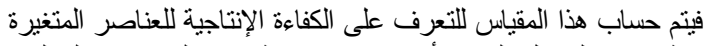

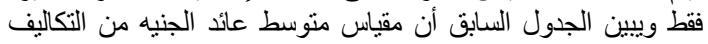

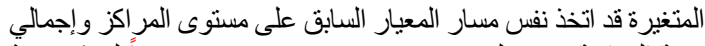

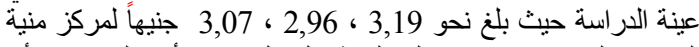

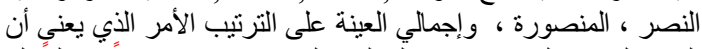

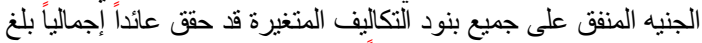

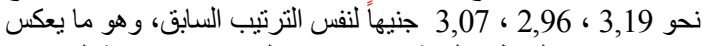
كفاءة مزارعى البصل بالعينة في استخدامها لمواردها الإنتاجية المتغيرة.

جدول 7. مؤشرات الكفاءة الاقتصادية لفدان محصول البصل فئل بمحافظة

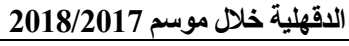

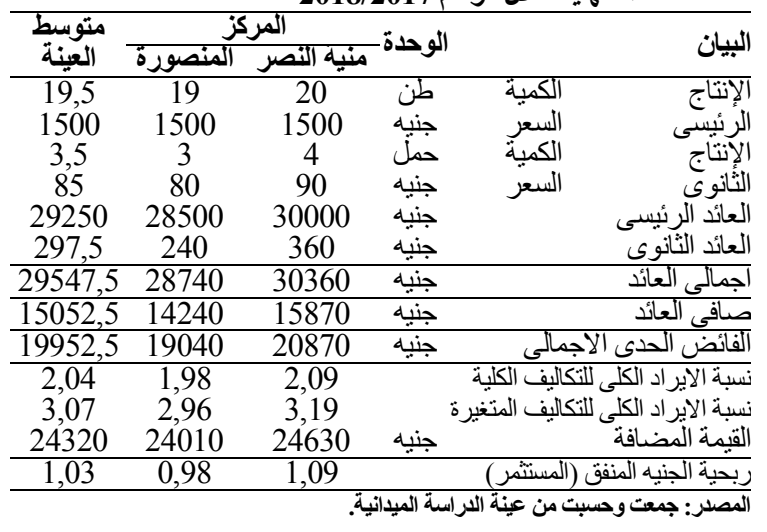

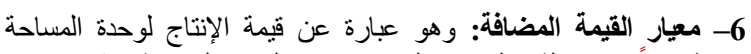

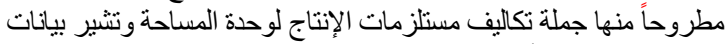

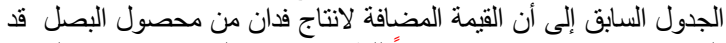

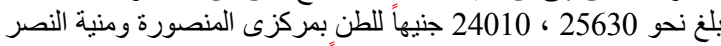

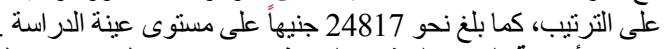

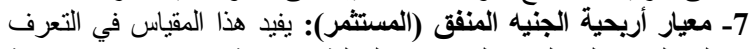

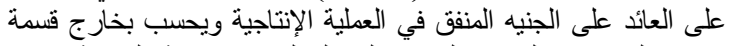

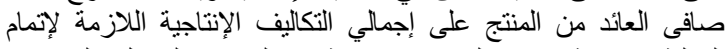

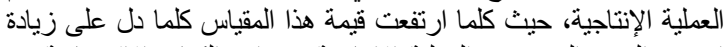

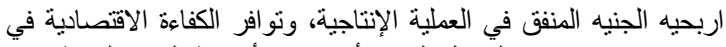

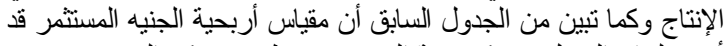

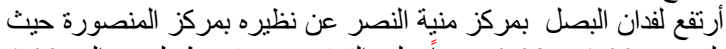

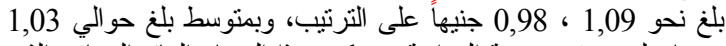

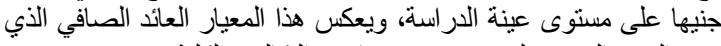
حققه الجنيه المنفق على جميع بنود عناصر التكاليف الكلية. 


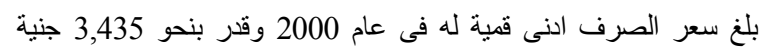

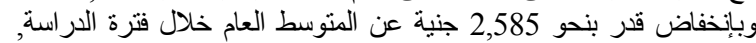

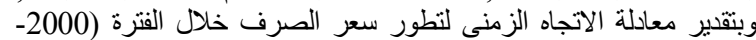

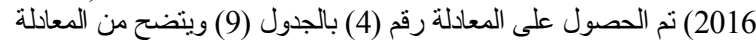

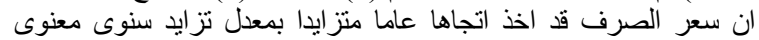

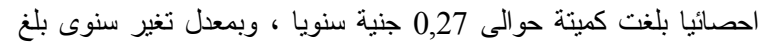
نحو\%,5\% وبلغت قيمة معامل التحديد نحو 70\%ة
من البصل قد اخذ اتجاها عاما متز ايدا بمعل زيادة سنوى معنوى احصائيا بلغت

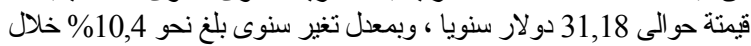

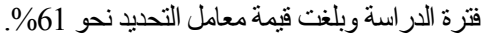
4- تطور سعر الصرف للاولار:

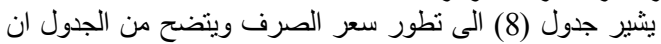

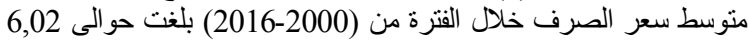

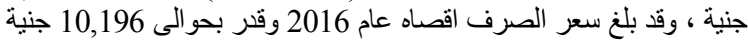

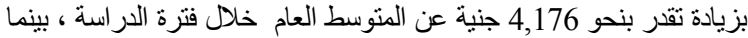

جدول 9. الاتجاه الزمنى العام لتطور كمية وقيمة الصادرات المصرية من البصل و السعر التصديرى وسعر الصرف خلال الفترة (2000-2016)

\begin{tabular}{|c|c|c|c|c|c|c|c|c|}
\hline قيمة F للمعادلة المسوبة & آقيمسة بحة & Rعامل Rالتحليد & السنوى التغيز) & متوسط الفرة & معامل الآحدار & الثابت & المتغير & 5 \\
\hline 18,74 & 4,32 & 0,55 & 5.7 & 329,2 & 18.6 & 161.7 & الكمينة (الف طن) & $\overline{1}$ \\
\hline 57,44 & 7,58 - & 0,79 & 13,9 & 110,2 & 15,36 & $28,12-$ & القيمة (مليون دولار ) & 2 \\
\hline$=23,35$ & 4.83 & 0.61 & 10,4 & 300.6 & 31,18 & 20.1 & ستر الطن (دولار) & 3 \\
\hline 38,39 & 6,19 & 0,70 & 4,5 & 6,02 & 0,272 & 3,57 & سعر الصرف & 4 \\
\hline
\end{tabular}

المصر : جمعت وحسبت من جلول رقم (8).

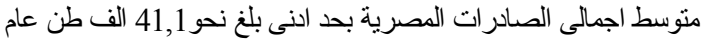

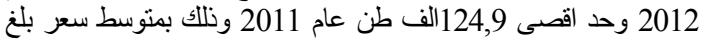

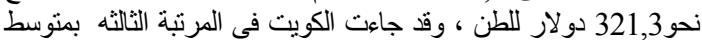

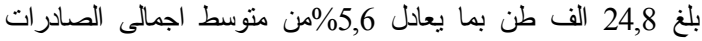

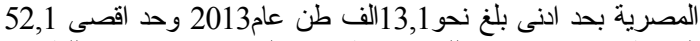

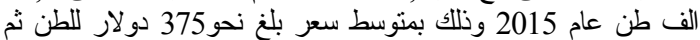

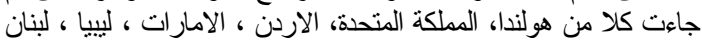

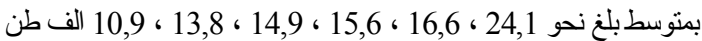

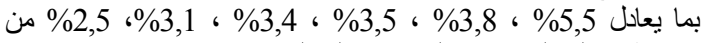

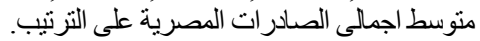

5- التوزيع الجغرافى للصادرات المصرية من محصول البصل خلال الفترة :2016-2011)

(أ) التوزيع الجغرافى لكمية الصادرات: بدراسة التوزيع الجغرافى للكميات

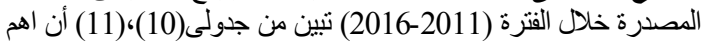

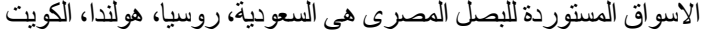

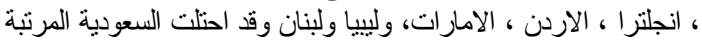

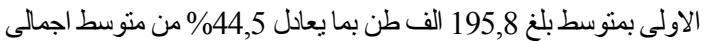

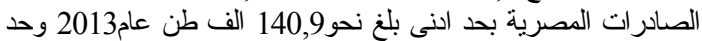

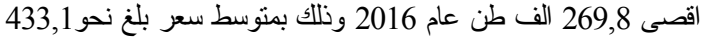

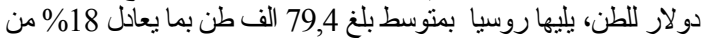

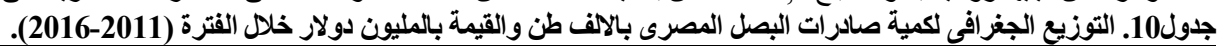

\begin{tabular}{|c|c|c|c|c|c|c|c|c|}
\hline \multicolumn{2}{|c|}{2016} & \multirow{2}{*}{\multicolumn{3}{|c|}{ كميل 2015}} & \multicolumn{3}{|c|}{2014} & \\
\hline فيمه & كمية & فيمه & & كميه & \multicolumn{3}{|c|}{ كميه } & \\
\hline 111,9 & 269,8 & 102,4 & \multicolumn{2}{|c|}{218,5} & 73,2 & \multicolumn{2}{|c|}{166,1} & \\
\hline 18,7 & 87,2 & 30,9 & \multicolumn{2}{|c|}{86,8} & 26 & \multicolumn{2}{|c|}{61,8} & \\
\hline 11,5 & 31,1 & 12,4 & \multicolumn{2}{|c|}{29,3} & 11,9 & \multicolumn{2}{|c|}{22,7} & \\
\hline 11,0 & 27,5 & 15,5 & \multicolumn{2}{|c|}{52,1} & 7,4 & \multicolumn{2}{|c|}{16,8} & \\
\hline 5 & & 7,4 & \multicolumn{2}{|c|}{22,9} & 13,7 & \multicolumn{2}{|c|}{26,2} & \\
\hline 4,5 & 11,2 & 8,7 & \multicolumn{2}{|c|}{19,5} & 5,3 & \multicolumn{2}{|c|}{11,5} & \\
\hline 1,5 & 4,4 & 27,9 & \multicolumn{2}{|c|}{65,2} & 3,4 & \multicolumn{2}{|c|}{6,8} & \\
\hline 6,9 & 17,2 & 2,5 & \multicolumn{2}{|c|}{8,1} & 4,2 & \multicolumn{2}{|c|}{8,2} & \\
\hline 5,8 & 21,1 & 3,3 & \multicolumn{2}{|c|}{9,4} & 2,8 & \multicolumn{2}{|c|}{6,4} & \\
\hline 177,6 & 479 & 211 & \multicolumn{2}{|c|}{511,8} & 148,4 & \multicolumn{2}{|c|}{326,5} & \\
\hline 16, & 36 & 24,3 & \multicolumn{2}{|c|}{45,5} & 20,1 & \multicolumn{2}{|c|}{40,4} & \\
\hline 193,9 & 515 & 235,3 & \multicolumn{2}{|c|}{547,4} & 168,5 & \multicolumn{2}{|c|}{366,9} & \\
\hline \multicolumn{9}{|c|}{ 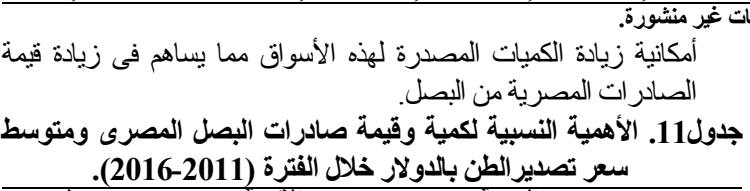 } \\
\hline متوسط سعر & & القيمة & & & الكمية & & & \\
\hline الطن & $\%$ & دولار & & $\%$ & & & & \\
\hline 433,1 & 44,5 & & & 44,5 & & & & \\
\hline 312,3 & 13 & & & 1 & & & & \\
\hline 459,8 & 5,8 & 1 & & 5,5 & & & & \\
\hline 375,0 & 4,9 & & & 5,6 & & & & \\
\hline 500,0 & 4,4 & & & 3,8 & & & & \\
\hline & 3 , & & & 3 , & & & & \\
\hline & 3,4 & & & 3,4 & & & & \\
\hline 449,3 & 3,3 & & & 3,1 & & & & \\
\hline 376,1 & 2,2 & & & 2,5 & & & & نار \\
\hline & 85,3 & 16 & & 76,2 & & & & \\
\hline & 14,7 & & & 23,8 & & & & \\
\hline 433,1 & 100 & 19 & & 100 & & & & \\
\hline
\end{tabular}

للمعتومات، بيلتات غير منشورة المركات

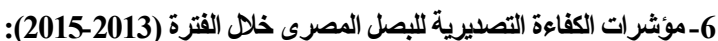

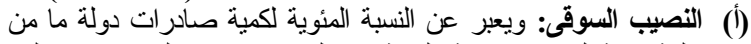
سلعة معينة الى سوق معينة بالنسبة لاجمالى واردات هذا السوقة السوق من مختلف

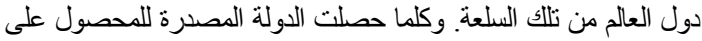
نسبة اكبر من النصيب السوقى للدولة المستوردة كلما كانت الصادرات فلى للى على

\section{3}

فيمه فينه

140,9

74,5

25,4

13,1

17,9

14,5

5,8

$5,8 \quad 0,93$

$\begin{array}{cc}12 & 3,3 \\ 12 & \end{array}$

76,2
13,2

$13,2 \quad 41,1$

$7,6 \quad 16,1$

$5,9 \quad 13,5$

$6,8 \quad 11,7$

$10,1 \quad 21,4$

3,3

1,9
25,8

$53,4 \quad 136,73$

7,6

310

154,2

37,7

\begin{tabular}{|c|c|c|}
\hline \multicolumn{2}{|c|}{2011} & \multirow[b]{2}{*}{ البيان } \\
\hline قيمه & كميه & \\
\hline 83,4 & 168,6 & السعودية \\
\hline 40,8 & 124,9 & روسيا \\
\hline 9,9 & 19,6 & هولندا \\
\hline 10,2 & 26,1 & الكويت \\
\hline 6,7 & 11,9 & انجلتر | \\
\hline 7,4 & 15,8 & الاردن \\
\hline 2,6 & 5,7 & الامارات \\
\hline 3,2 & 9,8 & ليييا \\
\hline 4,2 & 9,4 & لبنان \\
\hline 168,4 & 391,8 & جملة \\
\hline 47 & 99 & اخرى \\
\hline 215,4 & 490,8 & الاجمالى \\
\hline
\end{tabular}

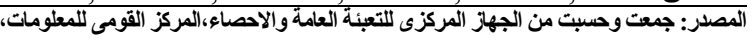

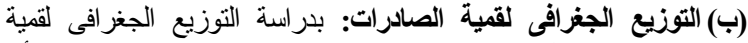

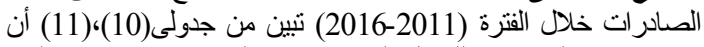

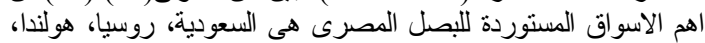

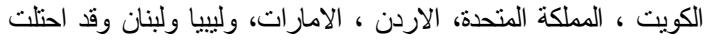

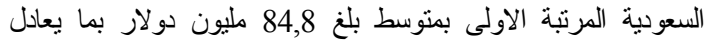

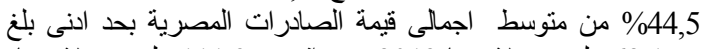

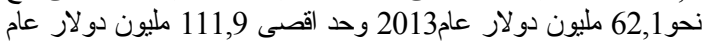

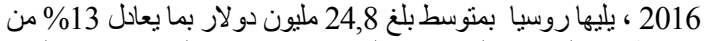

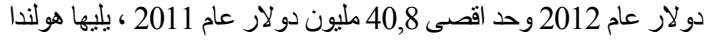

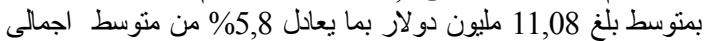

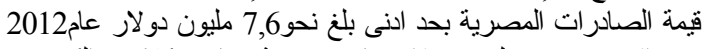

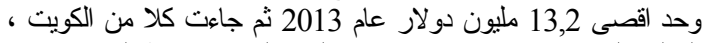

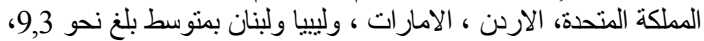

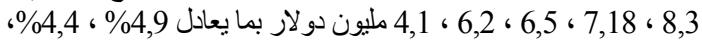

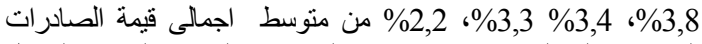

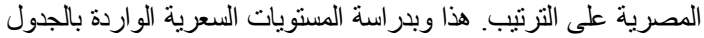

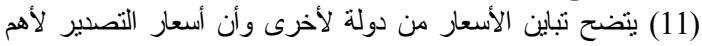

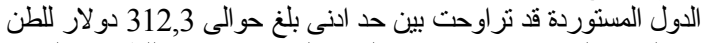

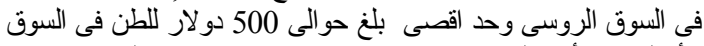

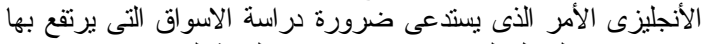

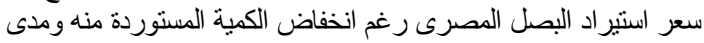

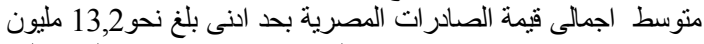




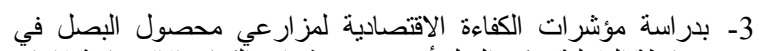

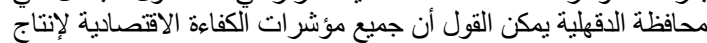

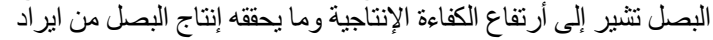

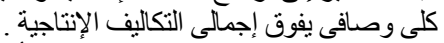
4- بدراسة الوضع التصديرى للبصل تبين النين أن منوسط كمية الصادرات

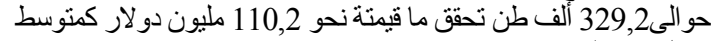

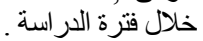

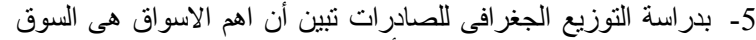

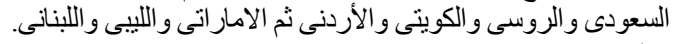
التوصيات

1- قيام الدولة بتشجيع الزراعات التعاقدية للمحاصيل التصديرية وخاصة

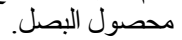

2- الاهتمام بتوفير قاعدة بيانات عن المحصول من حيث المساحة والإنتاج و الصادرات و الاسعار.

3- الاهتمام بجودة الإنتاج الموجة للتصدير وتخصيص مناطق للانتاج

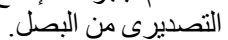

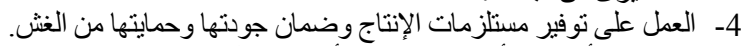
5- ضرورة الأهتمام بالأسو اق المرتفعة الأسعار وسبل زيادة الصنادرات اليها.

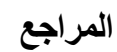

الاتحاد العام لمنتجى ومصدرى الحاصلات البستانية ، بيانات غير منشورة.

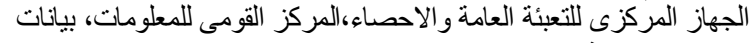
غير منشورة.

الجهاز المركزى للتعبئة العامة والاحصاء ، نشرة أسعار الجملة والتجزئة ، اعداد مختلفة لمئنة

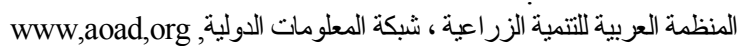
السيد البدوى جمال البحراوى ، الزية عفيفى على على عفيفى حمودة (دكاتزه)

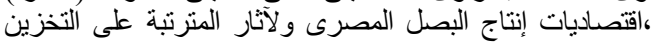

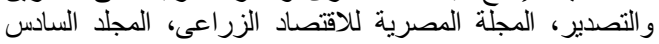

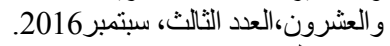

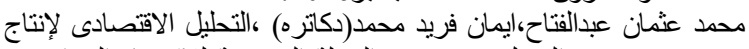

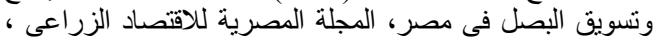

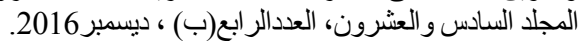

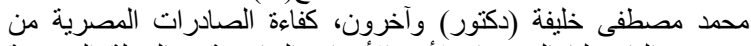

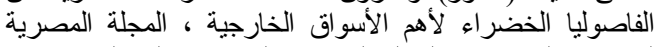

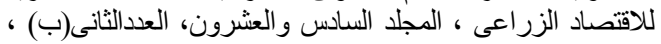

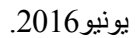

مديرية الزراعة بالدقهلية ، سجلات إدارة الإحصاء ، سجلات رسمية ، بيانات غير منشورة.

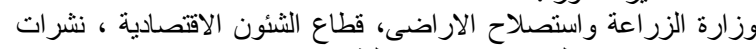
الاقتصاد الزر اعى، اعداد مختلفة.
وضع تتافسى افضل وبالتالى كان ذلك مؤشر ا على قوة نفاذها لهذا السوق

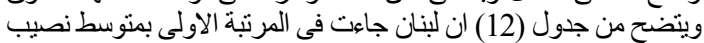

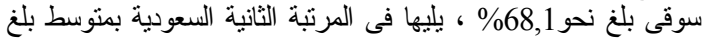

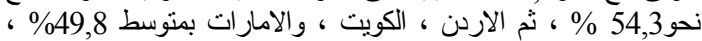

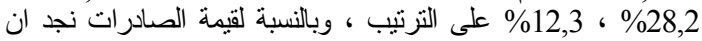

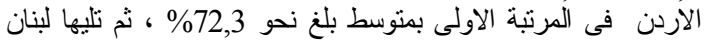

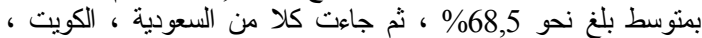

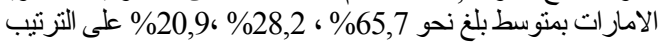

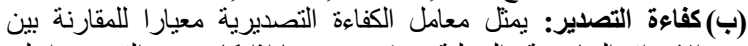

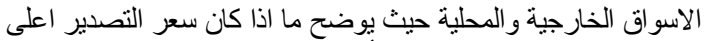

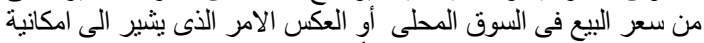

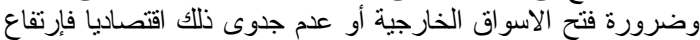

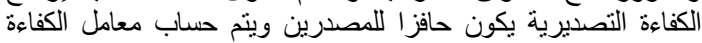
التصديرية من المعادلة التالية:

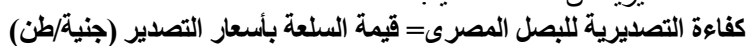

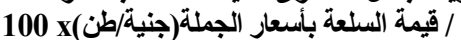

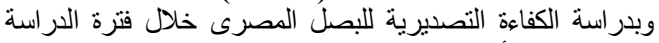

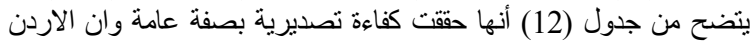

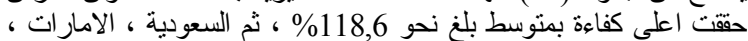

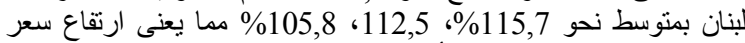

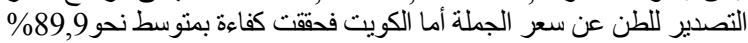

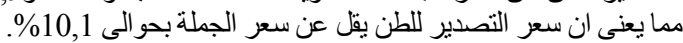
جدول 12. النصيب السوقى وكفاءة التصديرللصادرات النصات المصرية من البصل خلال القترة (2013-12)

\begin{tabular}{|c|c|c|c|c|c|c|}
\hline \multicolumn{2}{|c|}{ كفاعة التصدير } & \multicolumn{4}{|c|}{ النصيب السوقي } & \multirow[b]{2}{*}{ البيان } \\
\hline التترتيب & لكفاءة)(\%) & الترتيب & القيمة & الترتيب & الكمية & \\
\hline 2 & 115,7 & 3 & 65,7 & 2 & 54,3 & يعودية \\
\hline 5 & 89,9 & 4 & 28,2 & 4 & 28,2 & الكويت" \\
\hline 1 & 118 & 1 & 72,3 & 3 & 49,8 & ردّن \\
\hline 3 & 1. & 5 & 20,9 & 5 & 12,3 & مار ات \\
\hline 4 & 105,8 & 2 & 68,5 & 1 & 68,1 & لبنان \\
\hline
\end{tabular}

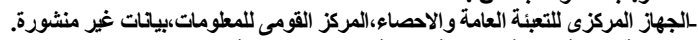

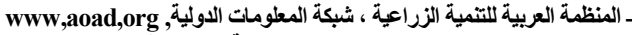

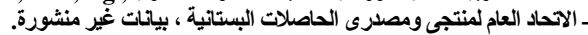

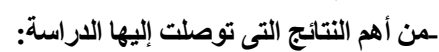

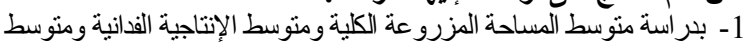

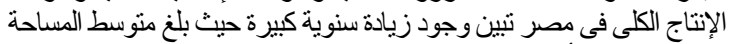

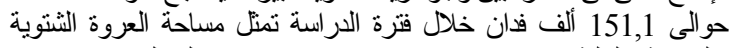

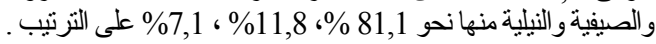

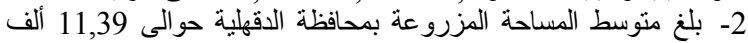

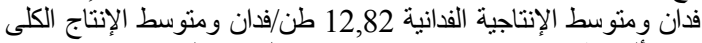

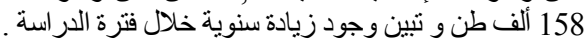

\section{An Economic Study of Onion Group Production and Exporting in Egypt}

\section{Ali, E. H. A.}

\section{Agricultural Economics Research Institute}

\section{ABSTRACT}

Onion is one of the most important the crops in Egypt, both at the level of domestic consumption or at the level of agricultural exports, Egypt enjoys a comparative advantage and is very competitive in onion production compared to many countries, Onions are grown in Egypt in three winter, summer and Nile varieties, Winter accounts for $91 \%$ The volume of onion exports is estimated at about 515 thousand tons estimated at about 193,9 million dollars in 2016. The problem of the study is that due to the economic importance of onion crop in Egypt in addition to its export importance and its role in providing foreign exchange, we find the fluctuation of cultivated areas by onion between decline and rise every several years at the level of Dakahlia in particular and the republic in general, which affects the instability of production And the value of Egyptian exports of onions. The study aims at shedding light on the onion production in Egypt and Dakahlia Governorate and the study of economic indicators for onion production in the study sample and the development of the quantity and value of Egyptian onion exports and the geophysical distribution of onion exports and the most important international markets for Egyptian onions, The research depended on the method of economic analysis descriptive and quantitative analysis, interpretation and description of economic variables and some measures and indicators of economic efficiency to produce onion crop in the two study centers in Dakahlia and some export indicators of onions, The study focused on two main sources of data, the first secondary data and the second preliminary data for the field study conducted through questionnaire form compiled by the interview of the onion farmers in Dakahlia governorate, The results showed that the average winter onion area is about 122,5 thousand fedan and the average total area of onion is 151,1 thousand fedan and the average total production is about 2 million tons, which exports 329 thousand tons during the period from 2000 to 2016, The most important foreign markets are the Saudi, Russian, Kuwaiti and Jordanian markets . 